IJHER International Journal of Humanities and Educational Research ISSN: 2757-5403

Volume 4, Issue 1, February 2022

\title{
RULES FOR GUARANTEEING THE UNIFORM APPLICATION OF VIENNA CONVENTION FOR INTERNATIONAL SALE OF GOODS 1980 AND FILL THE GAPS OF ITS PROVISIONS
}

\author{
Safaa Taqi ABD NOOR 1 \\ Prof. Dr, Mustansiriya University, Iraq \\ Asmaa Dawood SALMAN 2 \\ Researcher, Dewan Al-Waqf Al-Sonny, Iraq
}

\begin{abstract}
Vienna Convention arises many argumentative legal issues, which made the scholars deeply study its controversies, and the courts are conflicted in applying some of its provisions, and led to the necessity of researching in this convention due to the importance of this research paper which submitting good knowledge in relation with the application of Vienna Convention internationally, shows the fundamentals that should be taken in account, and it will provide a practical tool to the specialized people shows the valuable legal approaches in the way of applying some the convention's provisions. The purposes of this article fall under showing the mechanism of achieving the uniform application of Vienna Convention's provisions and knowing the effective factors in fostering the uniform application of its provisions. In addition, showing the mechanism of filling the gaps in its provisions, as well as, knowing the different judicial decisions in countries concerning the uniform application of the convention or gap filling.
\end{abstract}

Key words: CISG, Uniform application of CISG, Gap-Filling Under CISG.

http://dx.doi.org/10.47832/2757-5403.12.4 


\title{
قواعد ضمان وحدة تطبيق نصوص اتفاقية فينا

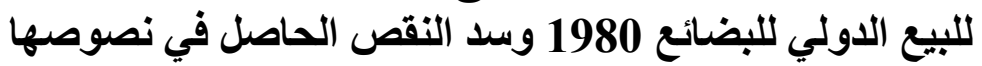

\author{
صفاع تفي العيساوي \\ أ. د ، الجامعة المستتصرية، العر اق اقعاع \\ أسماء داود سلمان العبيدي \\ الباحث، ديوان الوقف السني، العراق العيدي
}

تعد اتفاقية فيينا من الاتفاقيات التي اثارت الكثير من القضايا القانونية المثيرة للجدل التي جعلت الكتاب بتععقون في دراسة

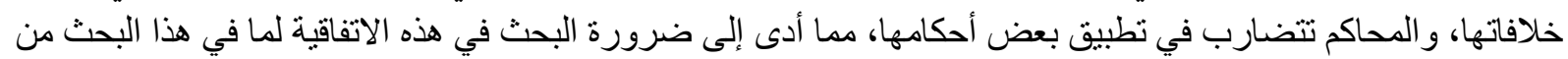

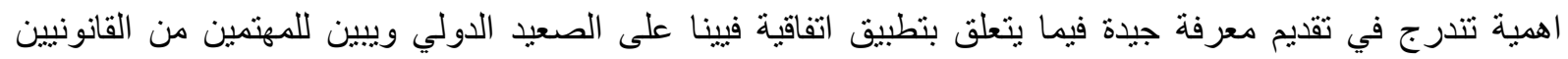

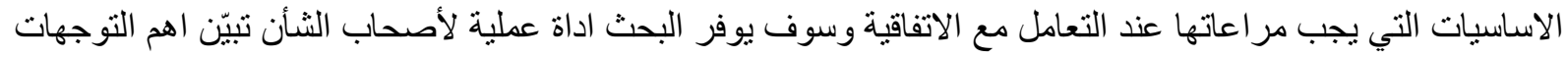

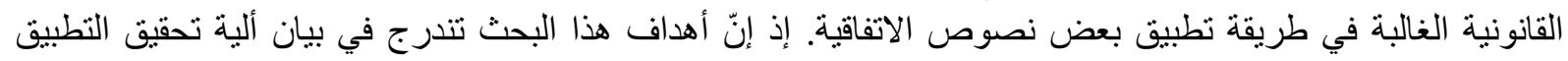

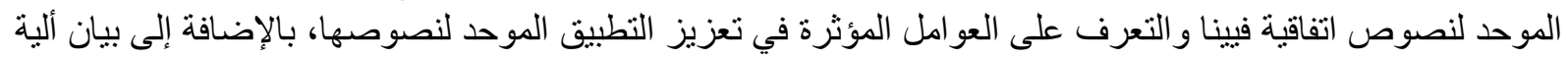

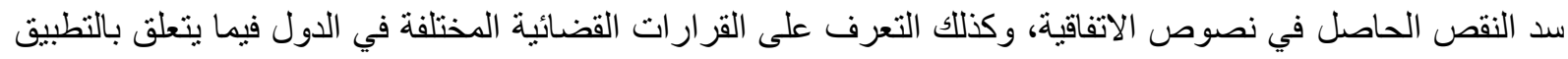

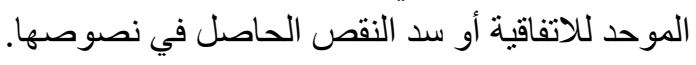

الكلمات المفتاحية: اتفاقية فيينا، التطبيق الموحد لاتفاقية فئية فيينا، سد النقص في اتفاقية فيينا.

المقدمة:

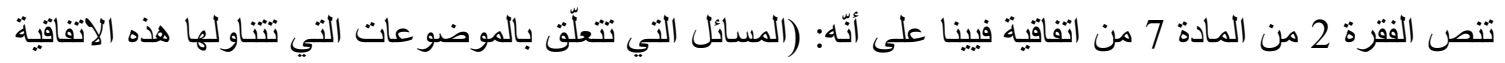

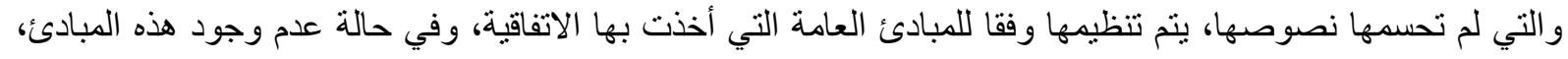

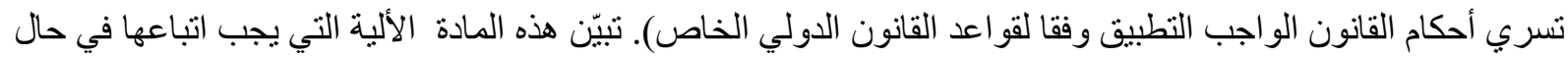

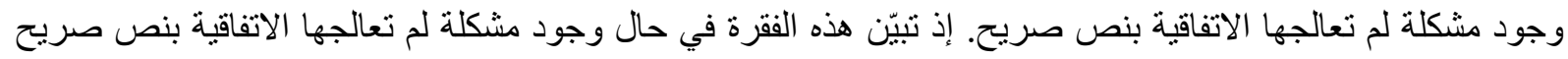

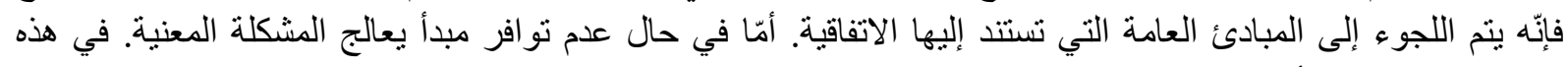
الحالة خوّلت المادة بأنّه يتم اللجوء إلى القانون المحلي الو اجب التطبيق وفقا للقانون الدولي الخاص ( Schlechtriem and

.(Butler, 2009

إنّ اتفاقية فيينا جعلت الكتّاب يتعِّقون في دراسة خلافاتها والمحاكم تتضارب في طريقة تطبيق بعض أحكامها

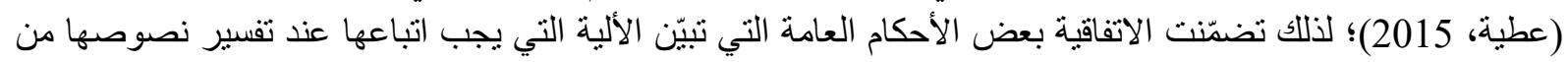

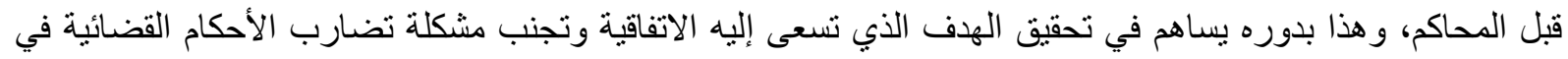

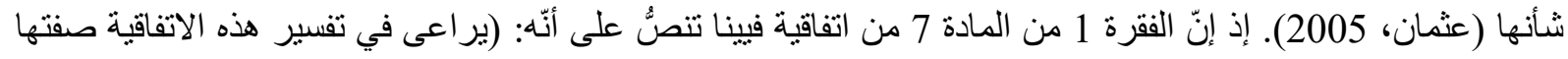

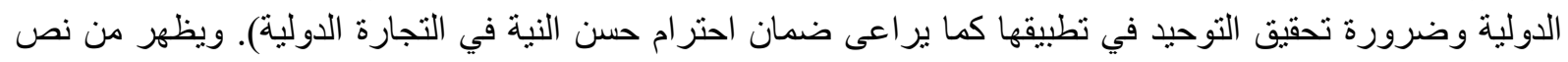

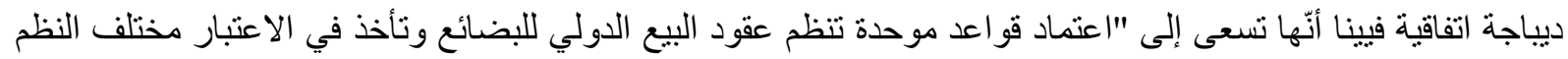

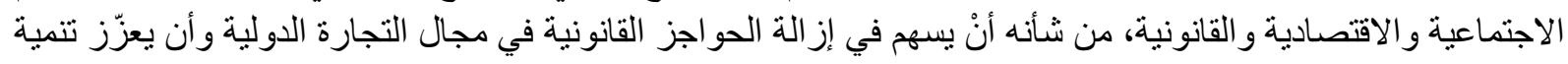

$$
\text { التجارة الدولية" (الصغير، الصناعة 2001). }
$$

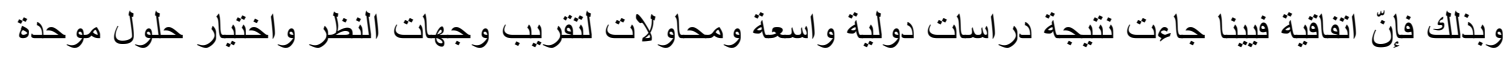

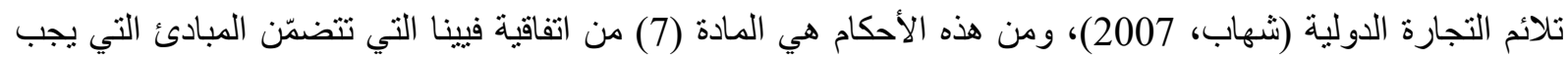

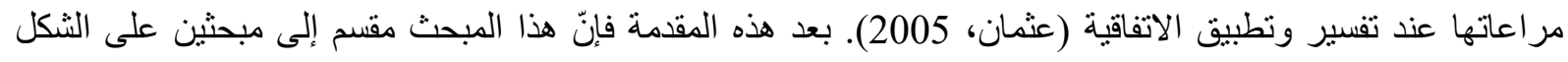
التالي: 
IJHER International Journal of Humanities and Educational Research

$$
\begin{aligned}
& \text { • • المبحث الأوّل: ضمان وحدة التطبيق. }
\end{aligned}
$$

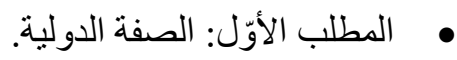

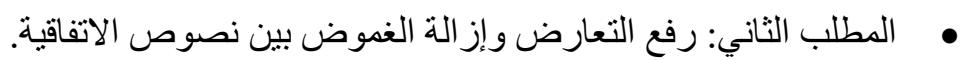

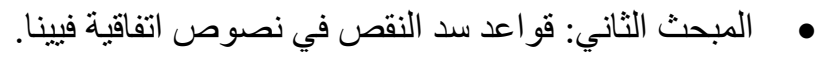

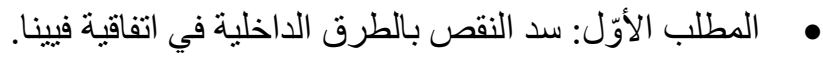

$$
\begin{aligned}
& \text { • المطلب الثاني: سد النقص بالطرق الخارجية في اتفاقية فيينا. }
\end{aligned}
$$


لبيان القواعد التي تضمن التطبيق الموحد للاتفاقية. تأتي الصفة الدولية في المقام الأوّل؛ وذلك لأنّ اتفاقية فيينا

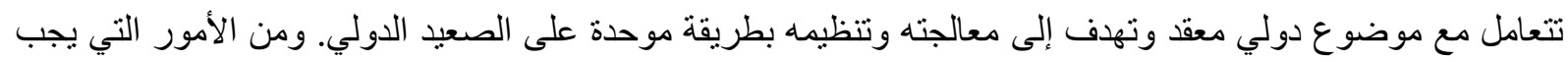

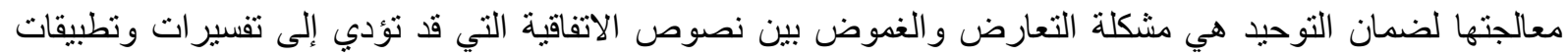

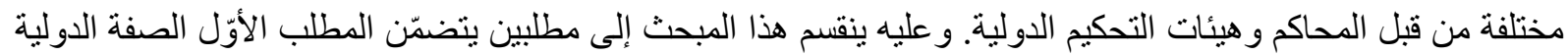

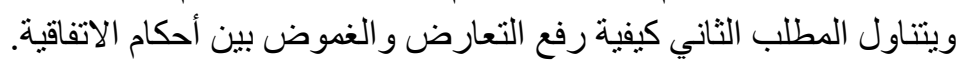

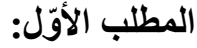 \\ الصفة الدولية}

تعاني القوانين التجارية المحلية الكثير من الخلافات في النهج والمفهوم المعتمد. وعليه كانت اتفاقية فيينا الحل

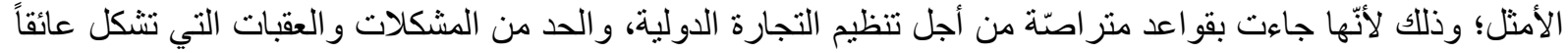

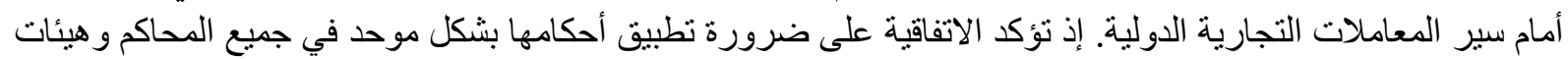

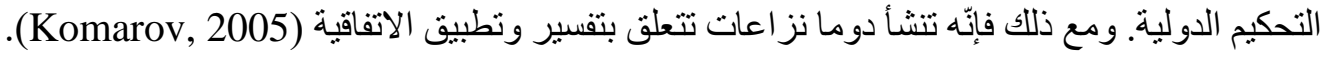

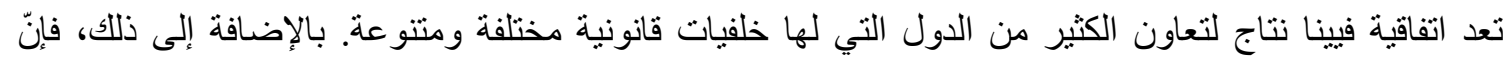

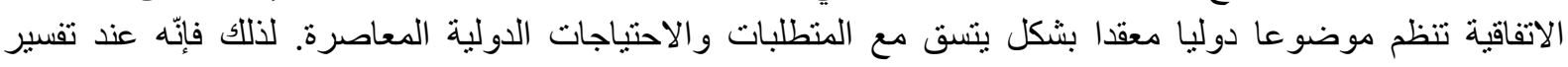

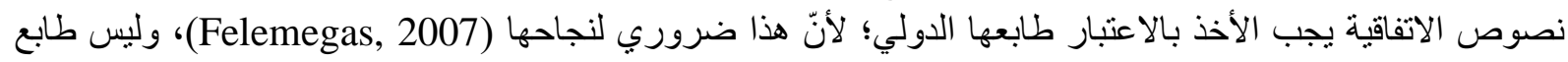

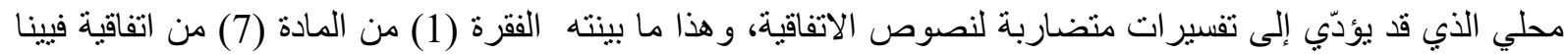

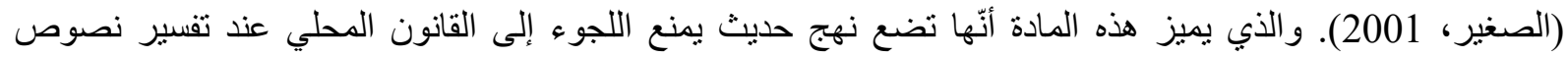

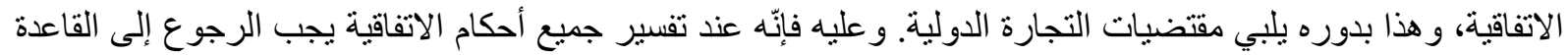
التي وضحتها المادة (7) اعلاه (Komarov, 2005).

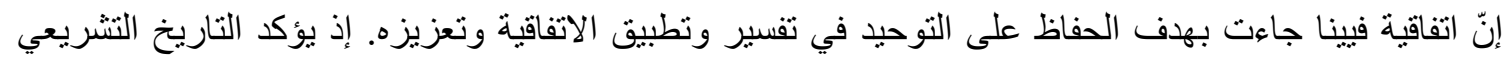

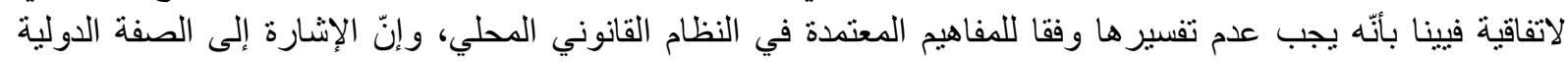

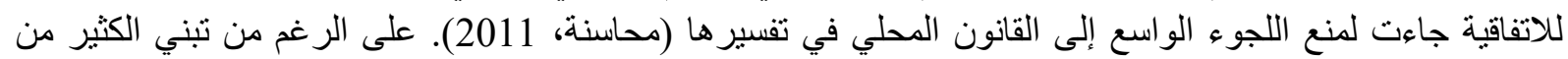

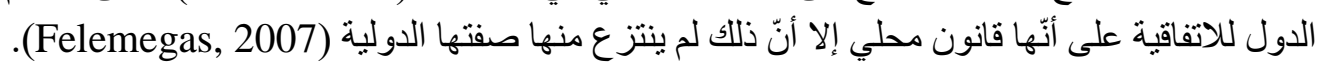

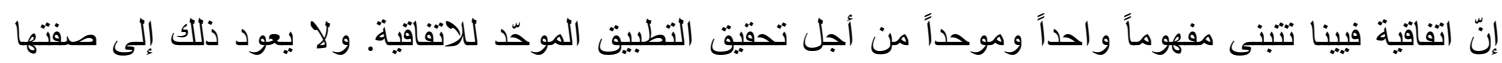

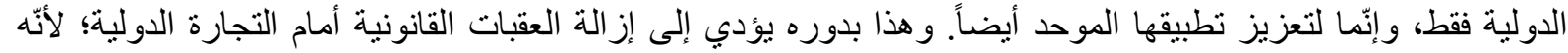

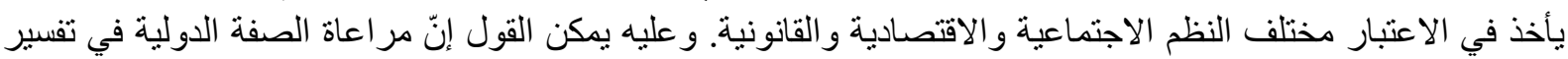

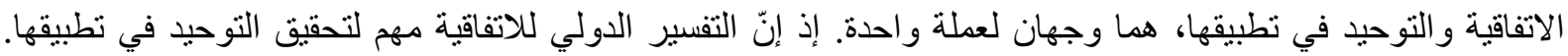

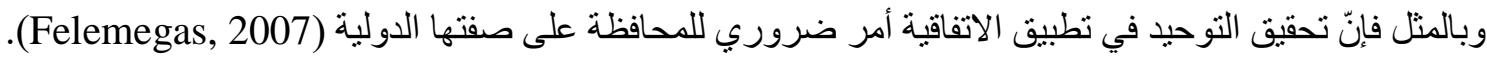

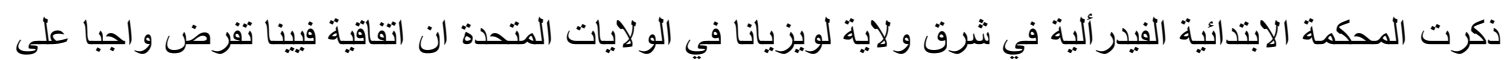

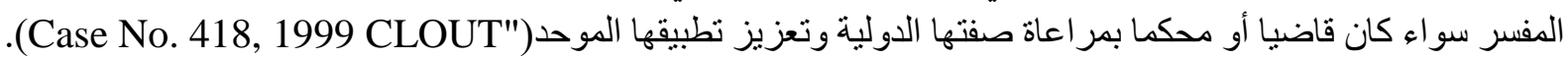

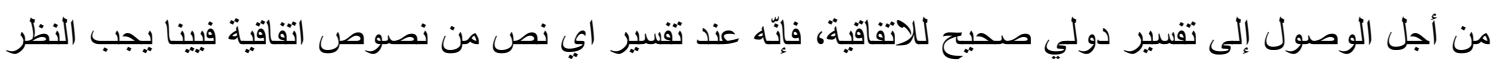

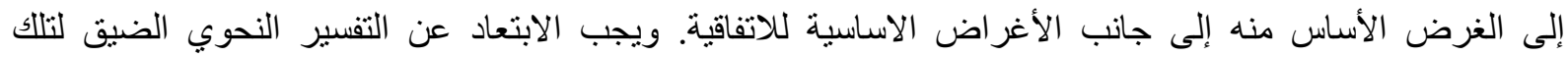

النصوص (Sollund, 2007)؛ لأنّ المبادئ الاساسية توفر تفسيراً اكثر دقة لأحكام الاتفاقية (Koneru, 1997).

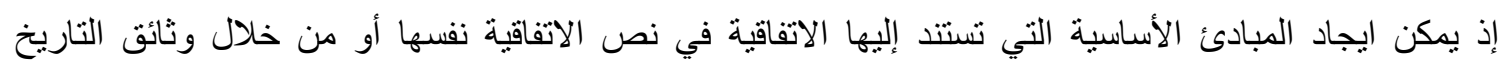
التشريعي لها أو مصادر أخرى. في حالة عدم ايجاد بعض المبادئ بشكل صريح في الاتفاقية، فيجب مر اعاة الهدف العام من الاتفاقية وصفتها الدولية عند البحث عن تللك المبادئ (Sollund, 2007).

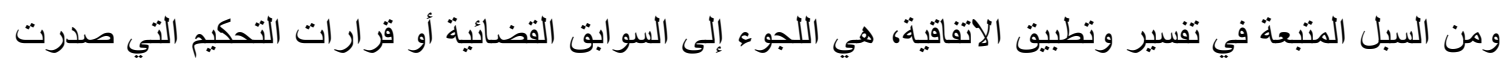

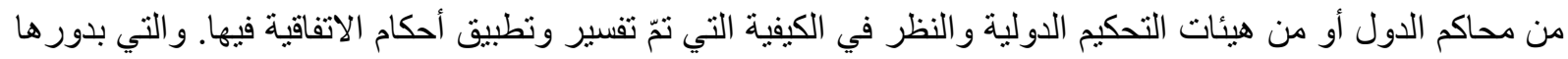

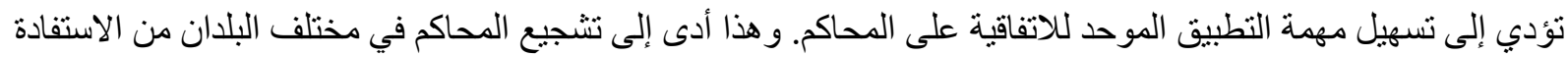


من الخبرة العملية في تطبيق الاتفاقية من السوابق القضائية لدحاكم الدول الاخرى أو القرارات التحكيم الدولية (Komarov, 2005)

على سبيل المثال، أقرت محكمة بافيا الإيطألية بأنّه على القاضي عند تفسير وتطبيق اتفاقية فيينا ان يأخذ في

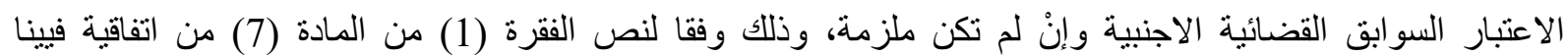

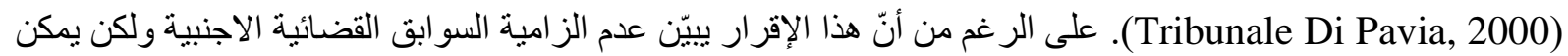

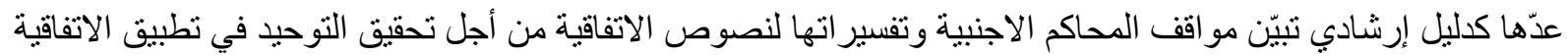
من خلال مر اعاة صفتها الدولية.

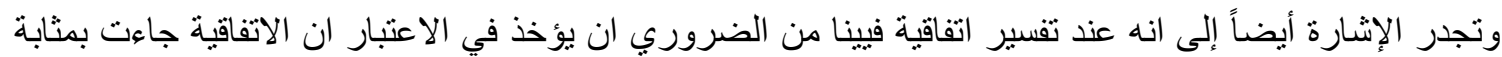

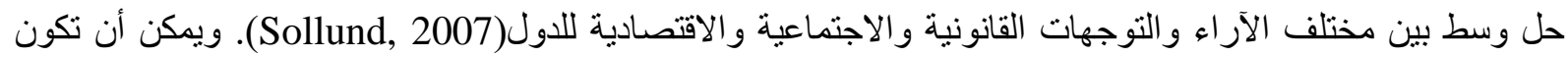

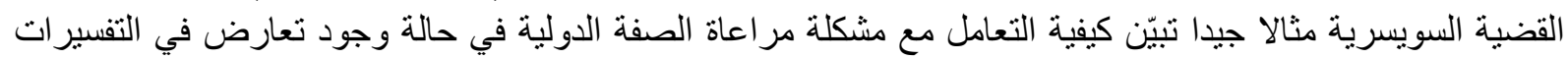
الدولية.

إذ أبرم بائع منتجات طبية ايطالي عقد بيع مع مشتري سويسري. تم الاتفاق بموجب العقد بأنّ يقوم البائع ببيع كمية

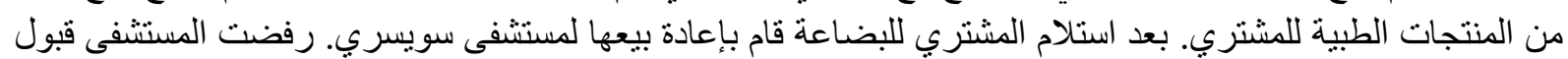

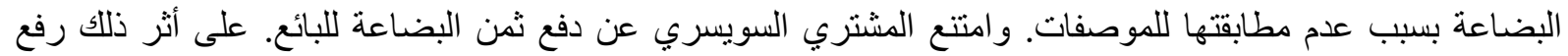

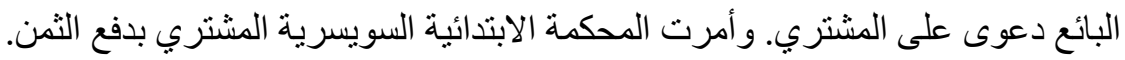

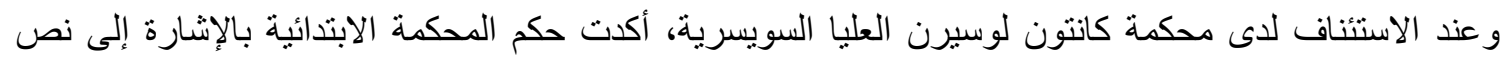

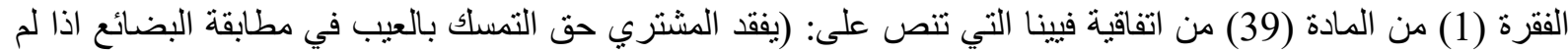

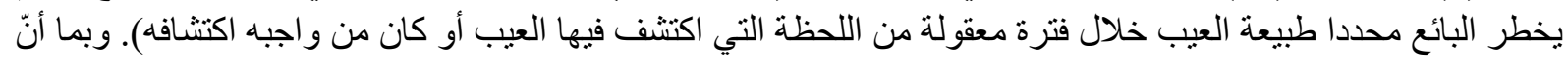

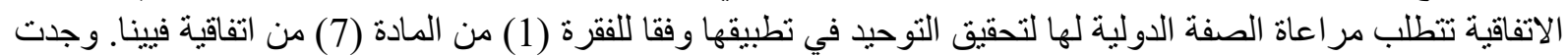

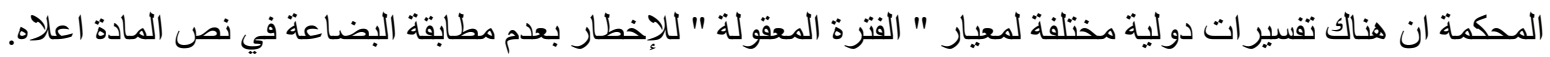

إذ وجدت في سوابق قضائية لمحاكم الولايات المتحدة وهولندا اعنبرت الفترة المعقولة للإخطار هي اقل من سنة

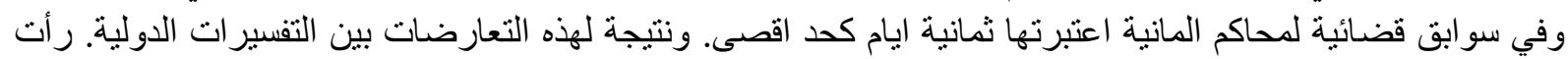

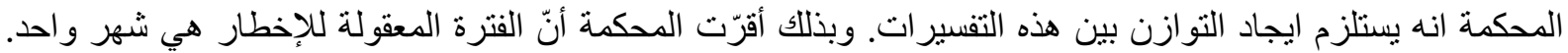

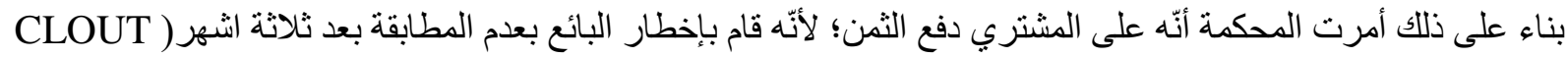

.(Case No. 192, 1997

$$
\text { المطلب الثاني: }
$$

\section{رفع التعارض وإزالة الفموض بين نصوص الاتفاقية}

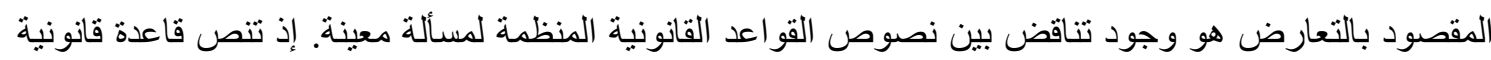
على أمر وتنص قاعدة اخرى على أمر يتعارض مع ما تلتص لتص عليه الأوّلى. مما يؤدي إلى الجمع بين الأحكام أو ترجيح

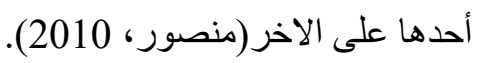

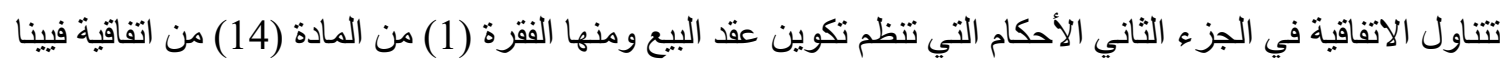

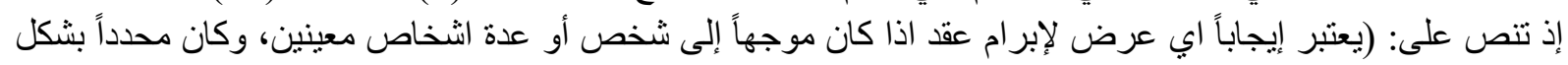

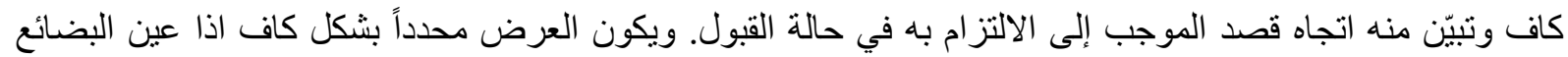

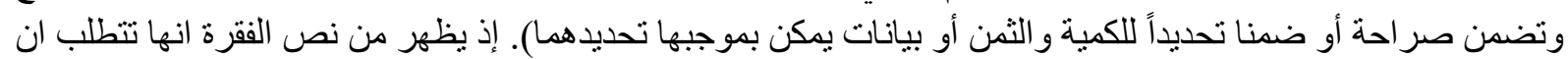

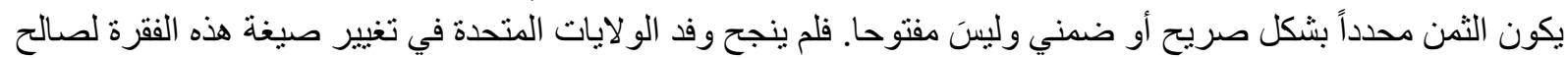

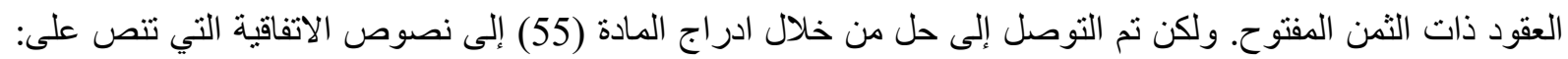

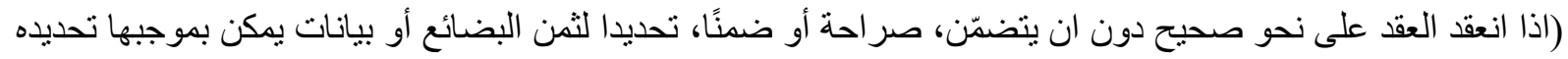

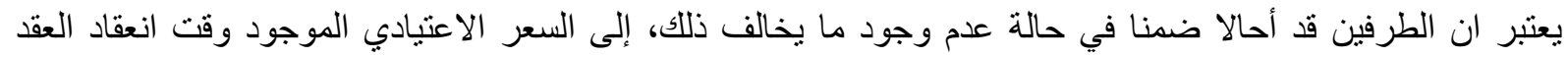

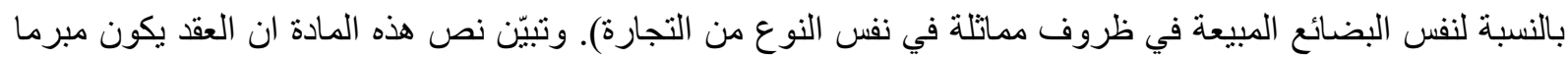

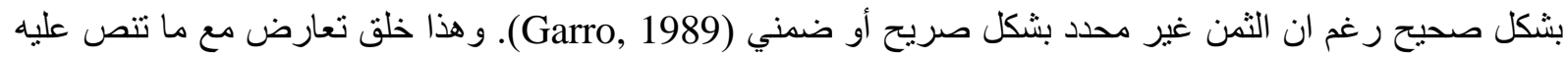

القاعدة في الفقرة (1) من المادة (14) من اتفاقية فيينا (Maggi, 2004). 


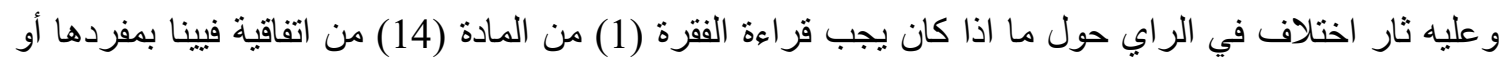

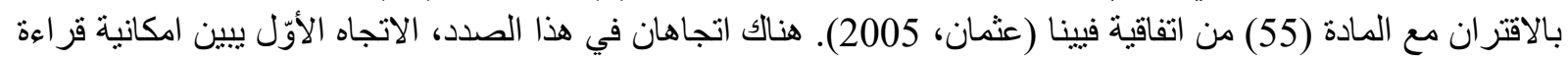

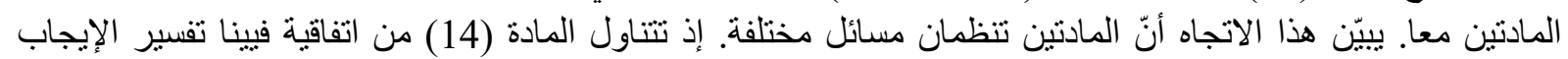

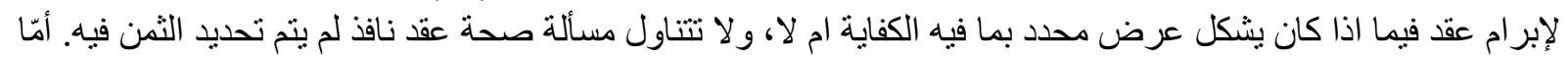

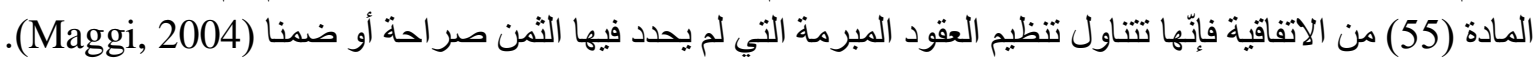

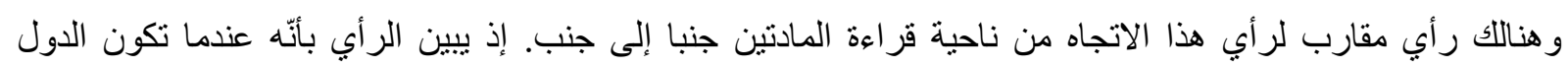

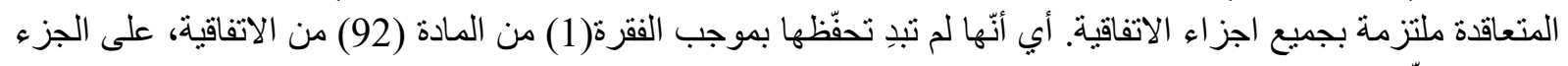

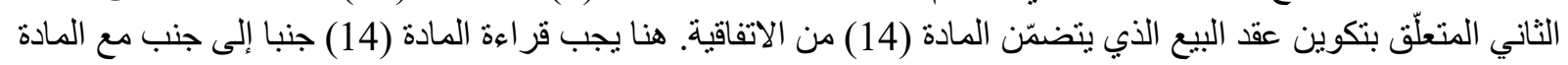

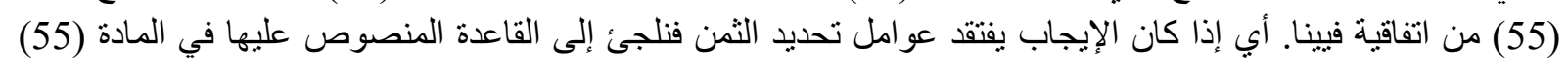

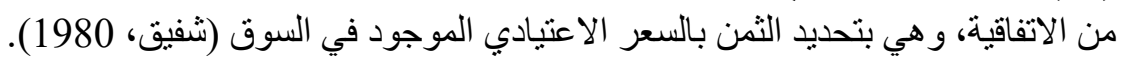

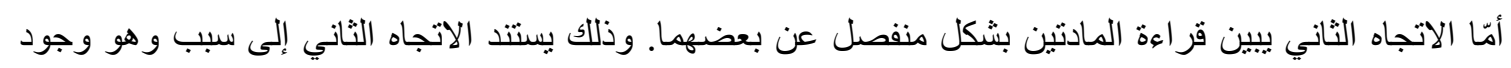

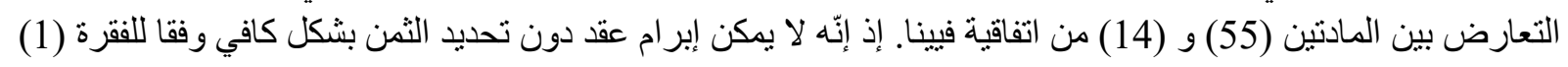

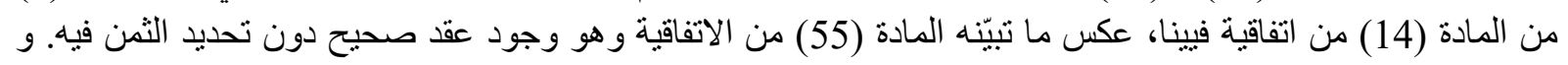

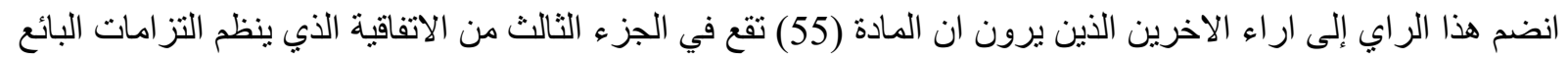

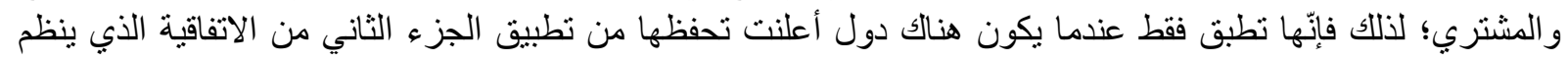
أحكام تكوين عقد البيع و الذي يضم المادئ فئ (14) (Maggi, 2004).

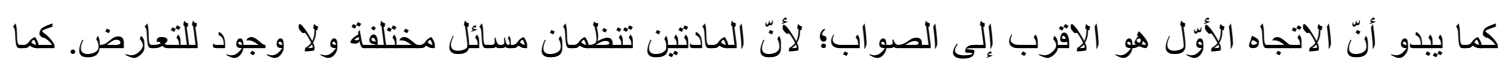

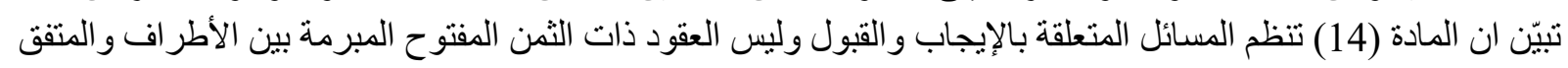
على الالتز ام بها التي تتناولها المادة (55) من الاتفاقية.

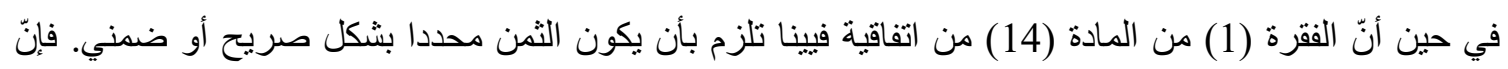

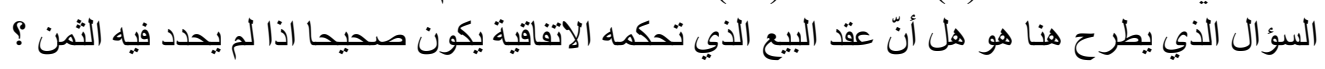

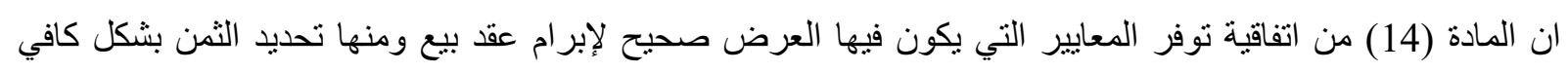

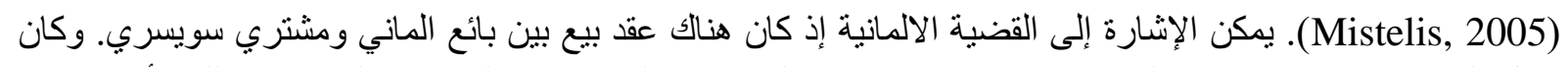

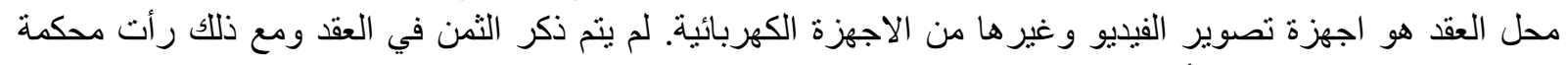

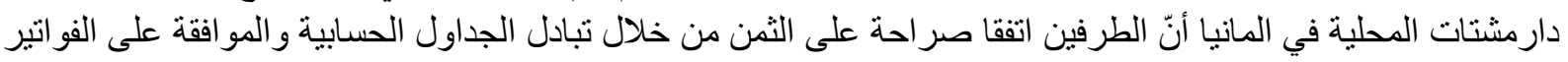

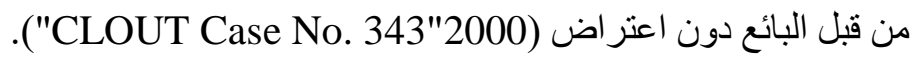

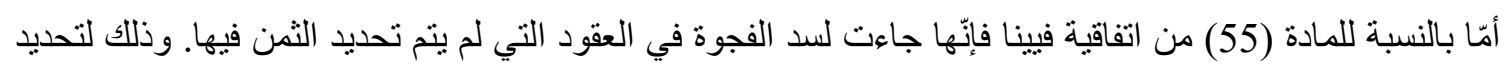

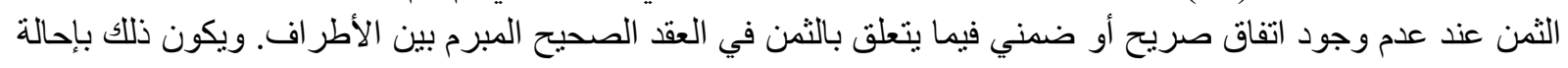

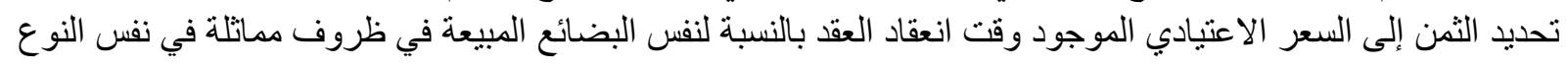

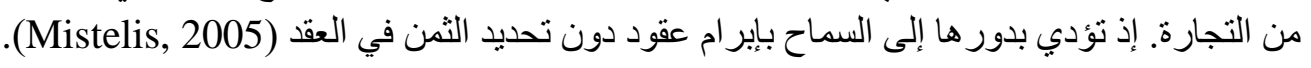

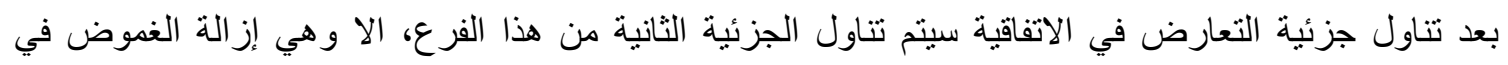

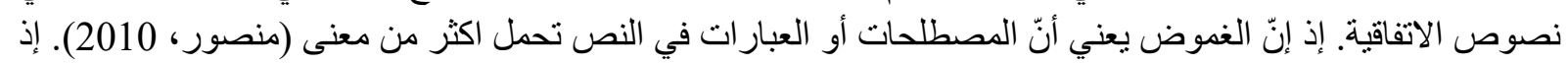

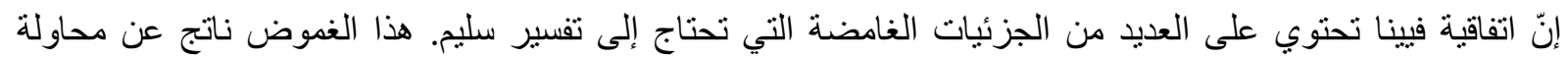

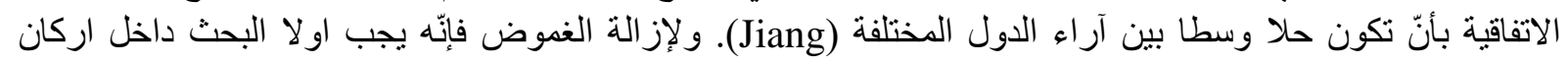

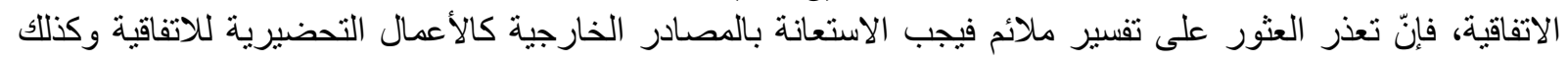

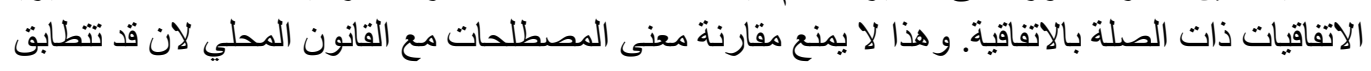

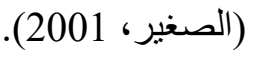

إن الفقرة (2) من المادة (16) من اتفاقية فيينا تتناول الحالات التي لا يجوز فيها الرجوع عن عن الإيجاب ففي البند (أ)

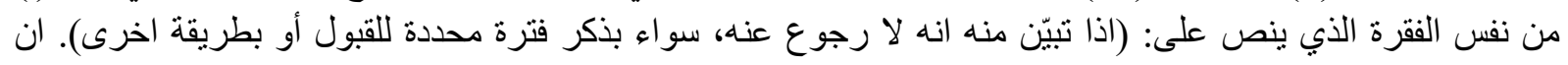

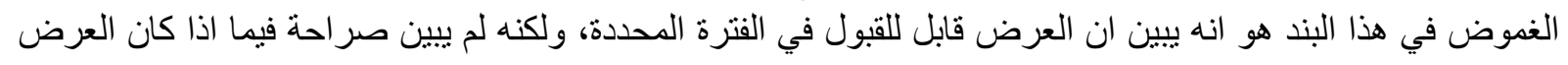

قابل للإلغاء قبل المدة المحدة (Gillette and Scott, 2005). 


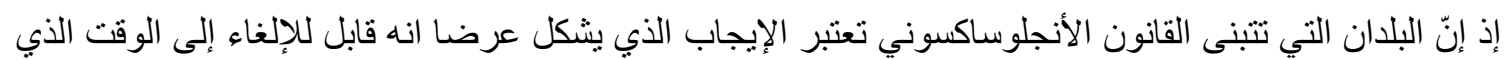

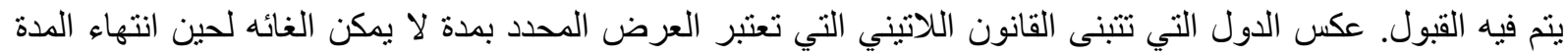

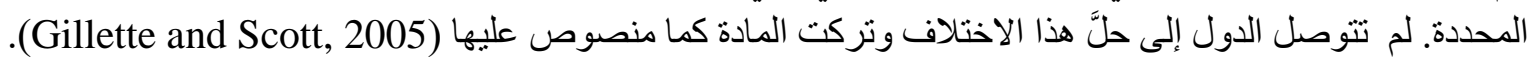

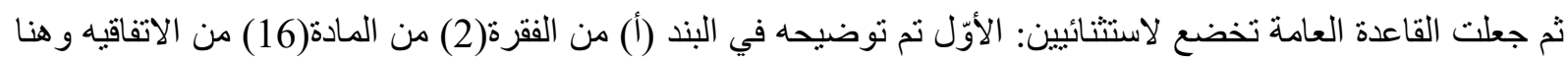

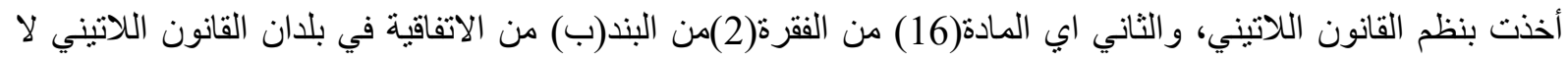

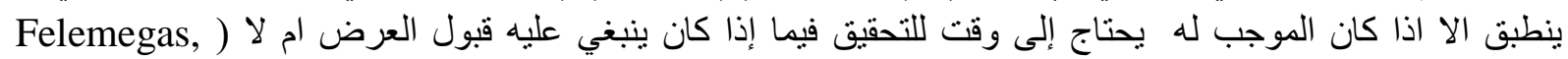




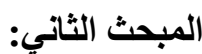 \\ قواعد سد النقص في نصوص اتفاقية فيينا}

يقصد بالنقص خلو النص أو أنْ يخفل النص حكم حالة كان يجب أن يتناولها بالحكم (البكري وبشير، 2019).

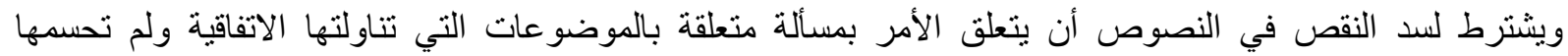

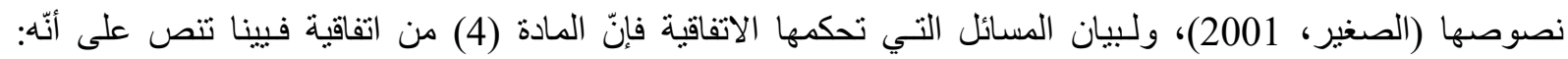

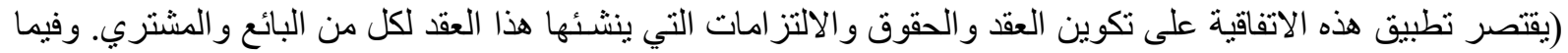

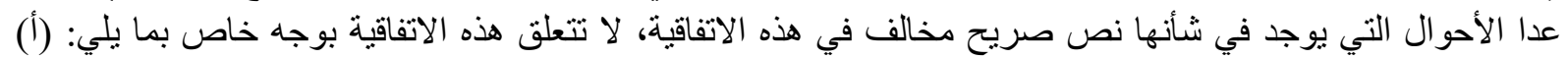

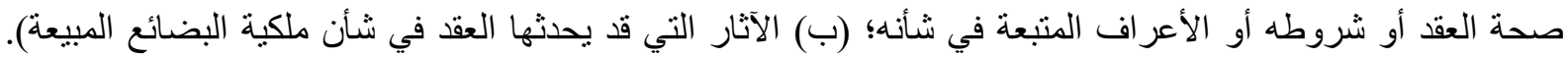

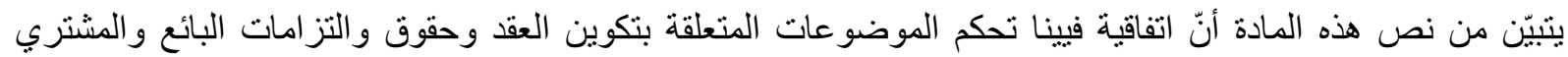

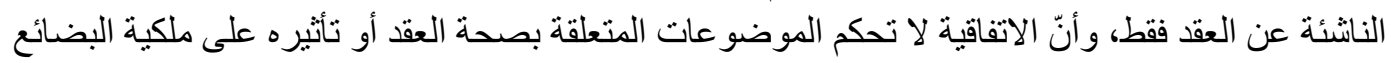
(Honnold and Flechtner, 2009) (Schlechtriem and Schwenzer, 2016). فيها و عليه ينقسم هذا المبحث إلى مطلبين، يتناول المطلب الأوّل سد النقص بالطرق الداخلية في اتفاقية فيينا ويتناول المطلب الثاني سد النقص بالطرق الخارجية في اتفاقية فيينا.

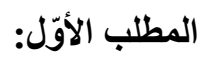

\section{سد النقص بالطرق الداخلية في اتفاقية فيينا}

عند وجود فجوة داخلية فإنّه يجب سـدها وفقا للمبـادئ العامة التي تستند إليها الاتفاقية. إذ إنّ ايجاد مبدأ مناسب لسد ولئ

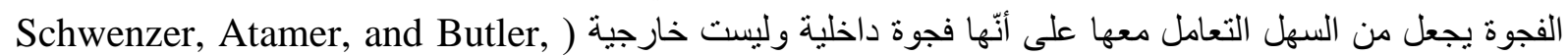

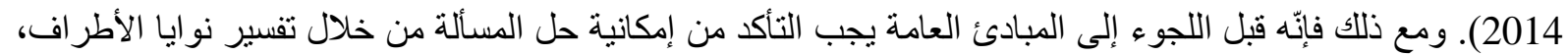

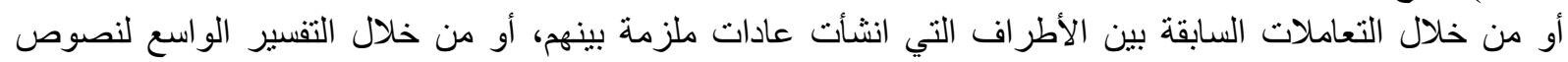
الاتفاقية، وكذلك من خلال القياس (Schlechtriem and Schwenzer, 2016).

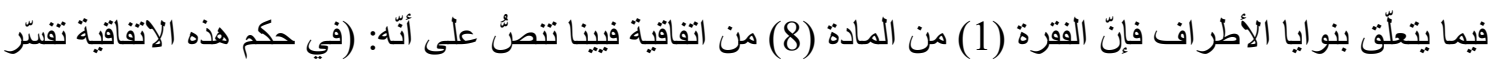

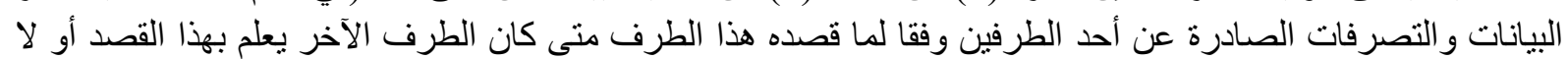

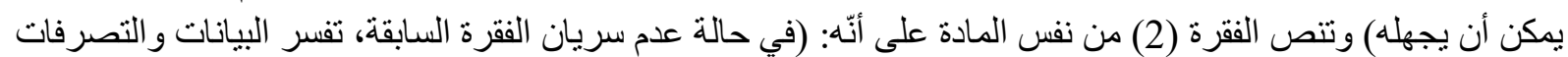

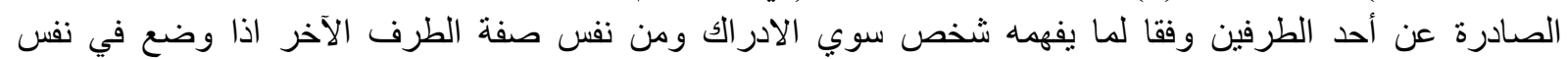

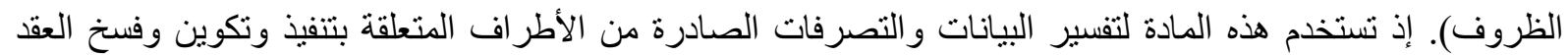

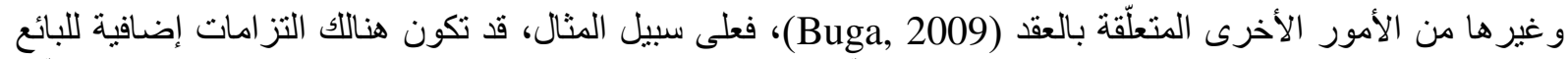

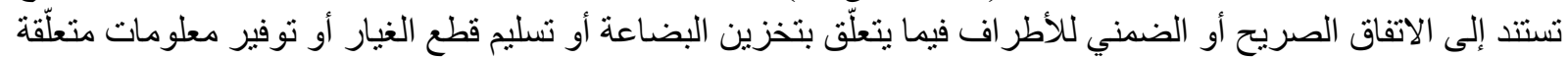

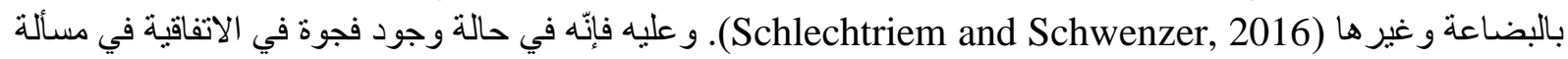

قد نظمها أطر اف العقد فيما بينهم صر احة أو ضمنا فيمكن سدها من خلال تفسير بياناتهم وفقا للمادة (8) من اتفاقية فيبنا.

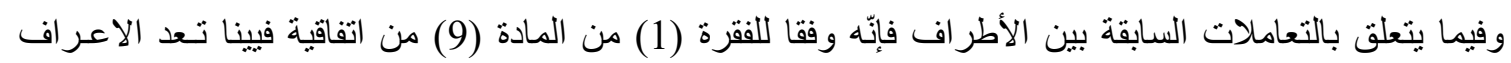

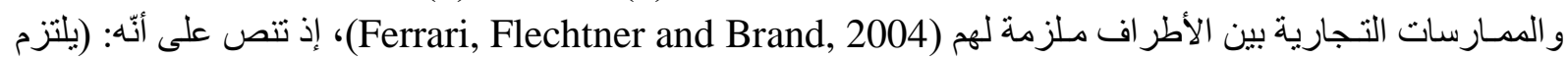

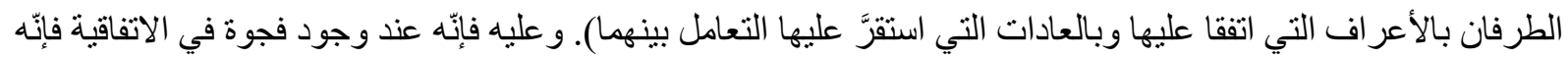

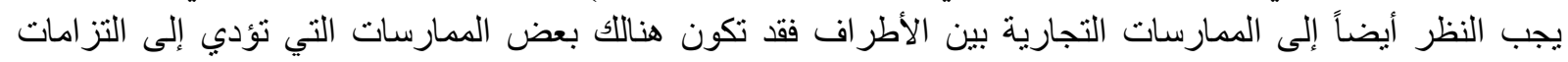

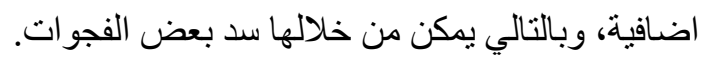

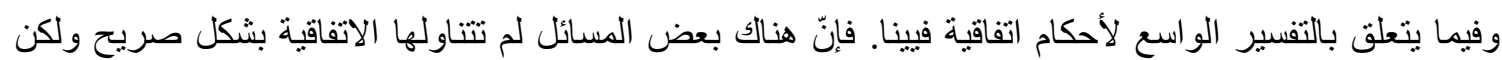

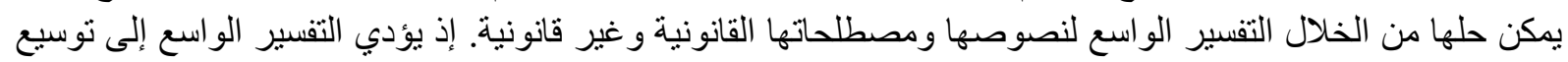

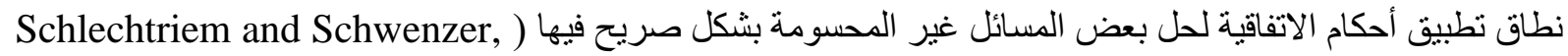

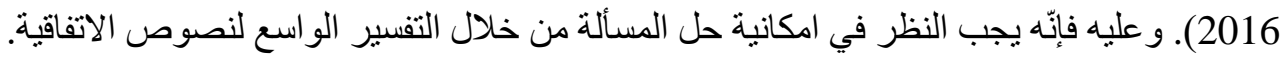


اما بالنسبة لسد الفجوات عن طريق القياس وهو اعطاء حالة غير منصوص على حكمها حكم حالة منصوص علئ عليها

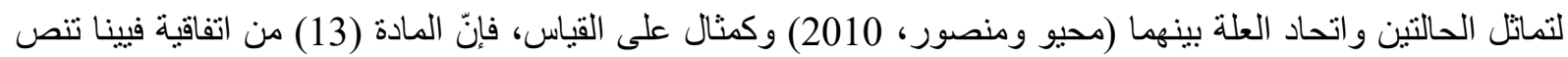

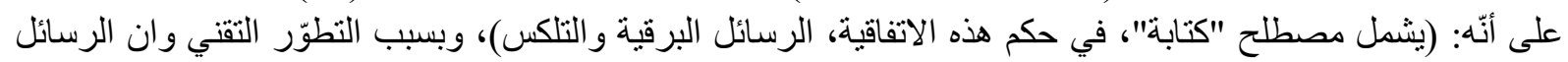

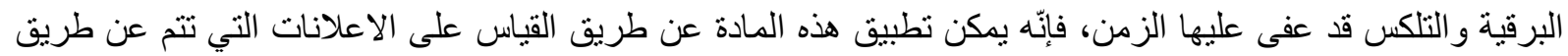

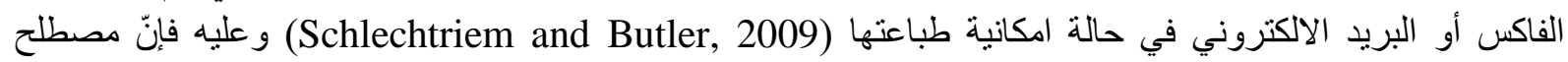
"كتابة" في اتفاقية فيينا يشمل رسائل البريد الالكتروني و الفئر الفاكس.

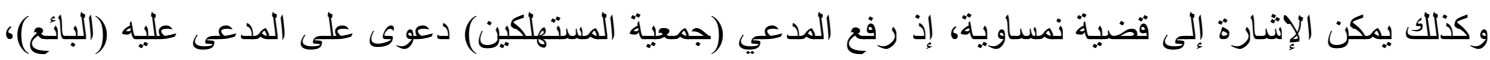

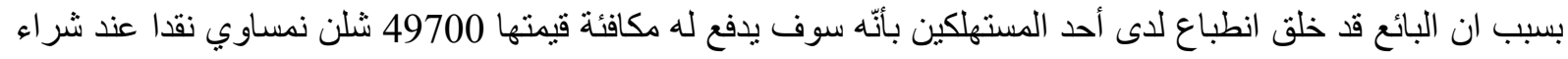

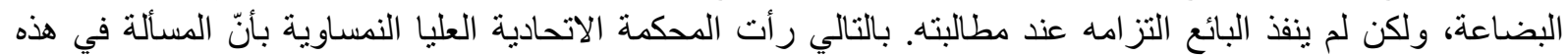

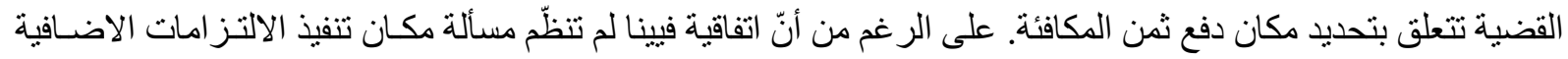

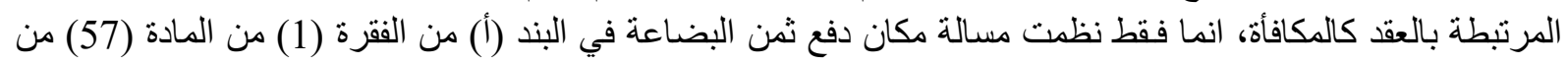

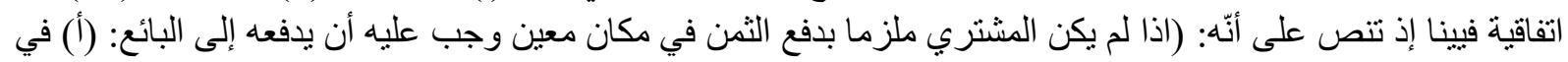

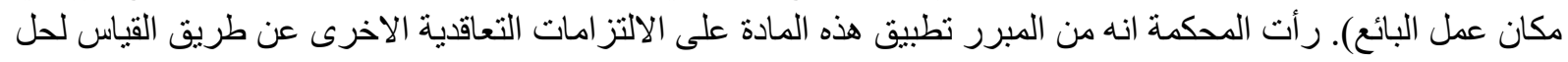

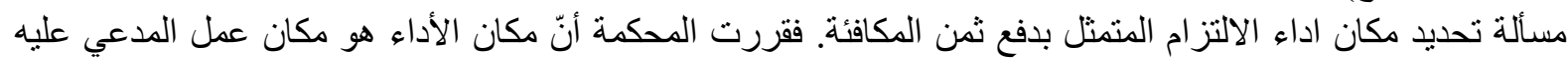

(Federal Supreme Court Of Austria, 2002)

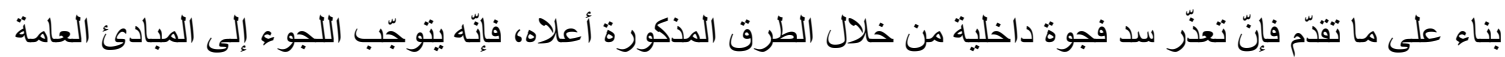

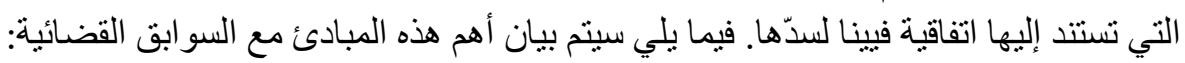
أولا: مبدأ استقلألية الأطراف.

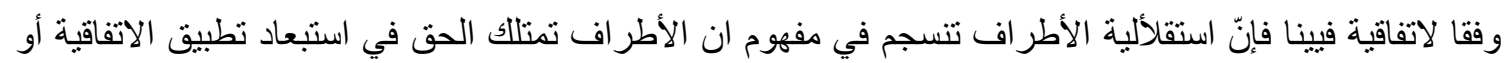

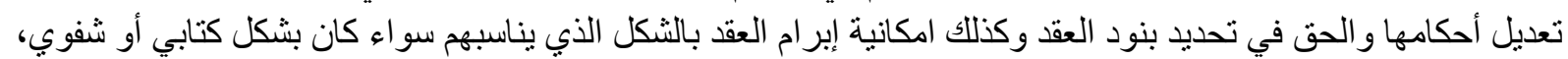
وكذلك الحق في نوقيع العقد من عدمه (GÜL, 2016).

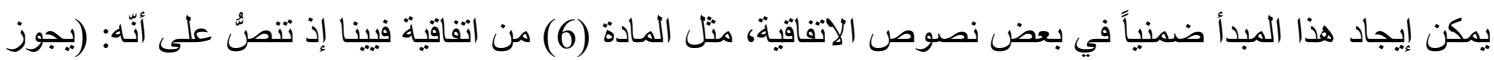

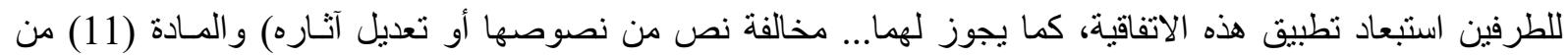

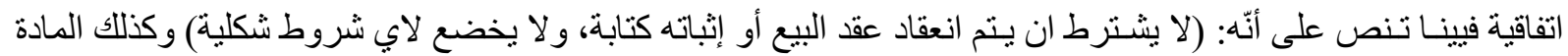
(9) من اتفاقية فيينا التي تسمح للاططر اف بالالتز ام بالأعر اف و العادات التي اتفقا عليها (Sica, 2006)

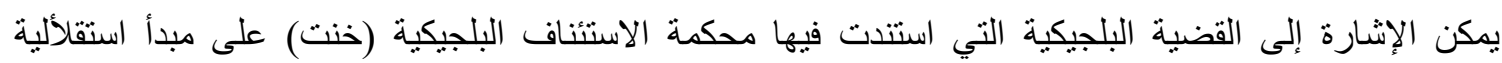

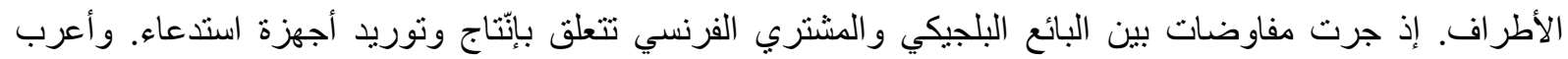

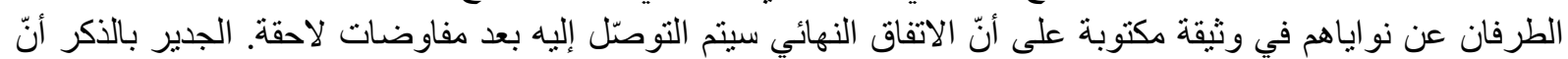

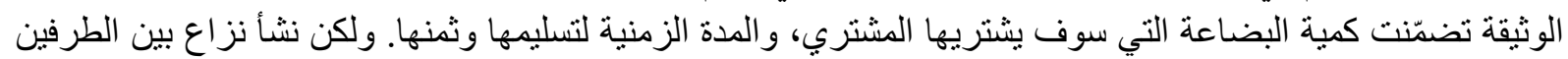

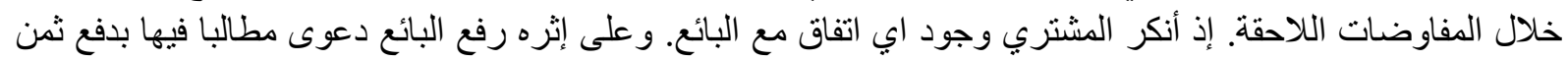

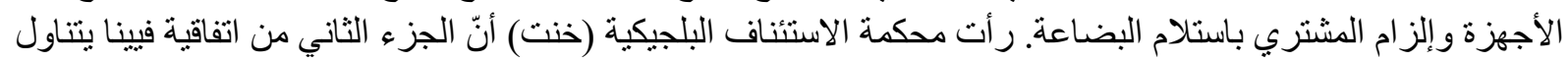

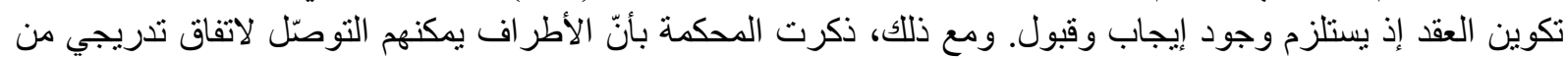

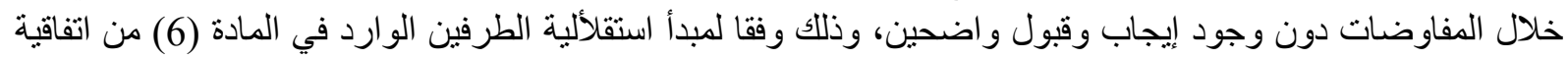

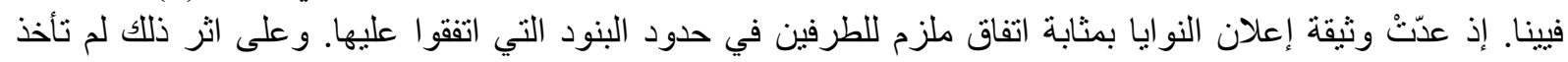

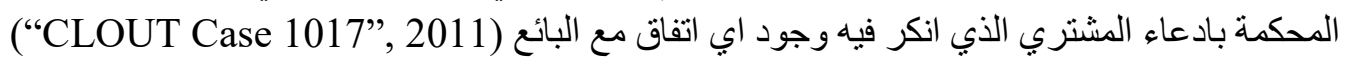

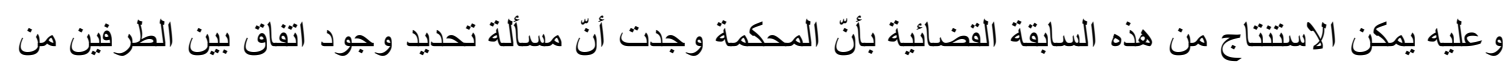

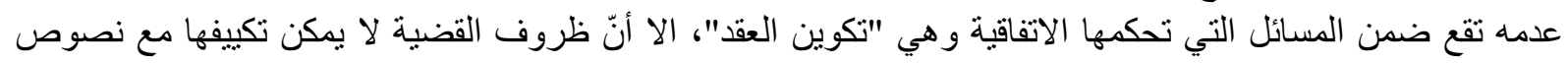

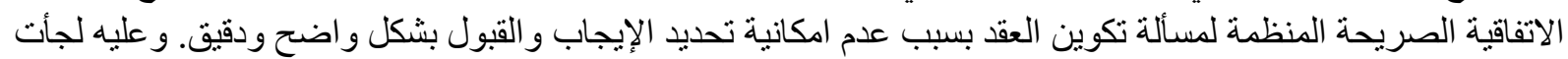
المحكمة للمبادئ العامة للاتفاقية لحسم المسألة لكنة 
من المهم تحديد أي من الأطر اف يتحمّل عبء الإثبات في النزاع (Janssen, Meyer, 2009). إذ إنّ اتفاقية فيينا

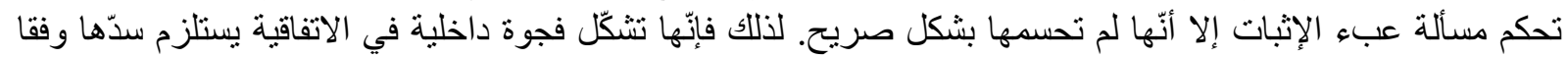

للمبادئ العامة التي تستند إليها الاتفاقية (UNCITRAL Digest, 2016)

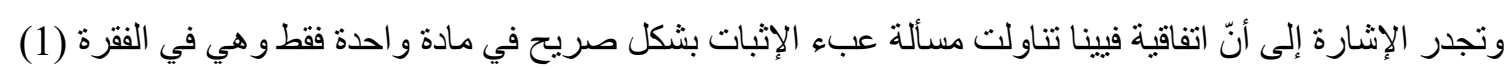

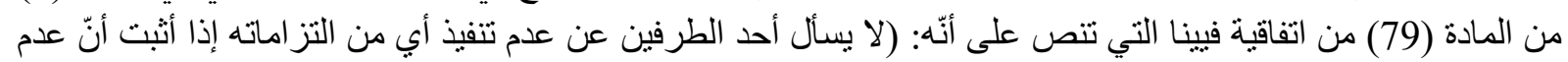

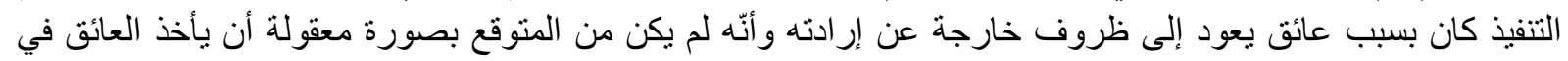

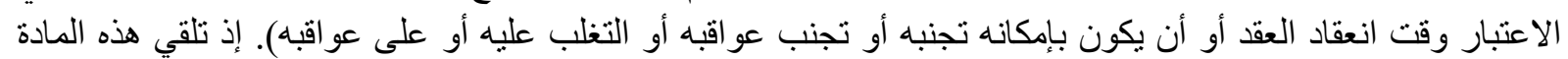

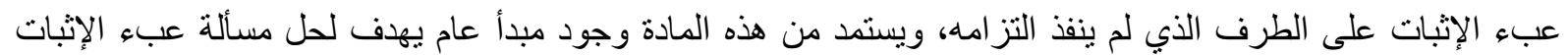

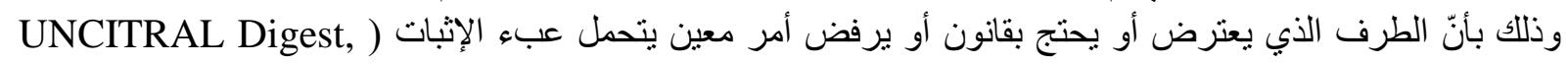

يمكن الإشارة إلى قضية ايطألية، إذ رفع المشتري دعوى على البائع ادعى فيها ان البضاعة غير مطابقة امام محكمة

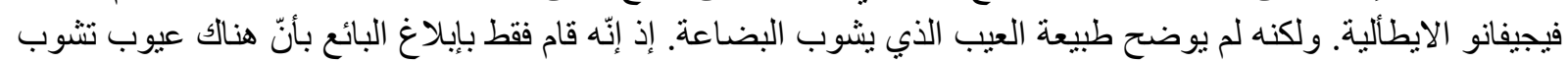

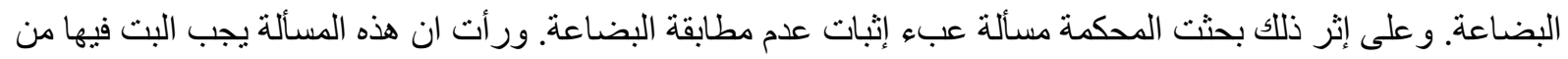

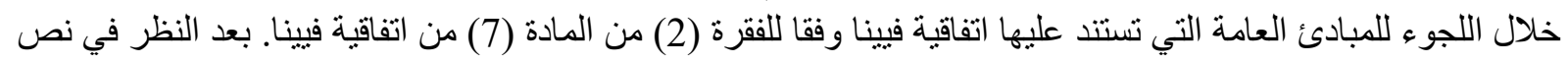

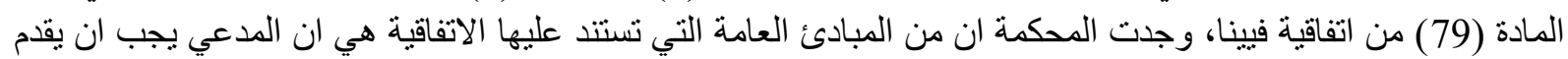

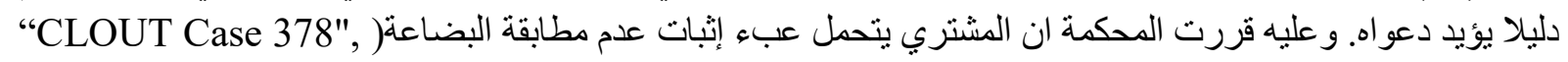

(2000

$$
\text { المطلب الثاني: }
$$

\section{سد النقص بالطرق الخارجية في اتفاقية فيينا}

عند وجود فجوة خارجية فإنّه يجب سدها من خلال اللجوء إلى القانون المحلي الو اجب التطبيق وفقا لأحكام القانون

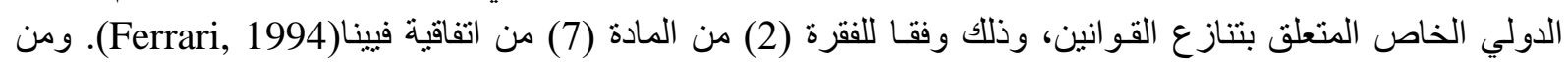

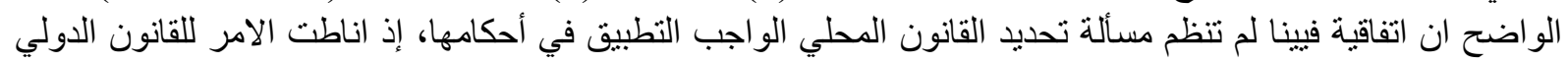
الخاص (تنازع القو انين) (Schlechtriem and Schwenzer, 2016). أدى الاختلاف في الآر اء بين الدول عند صياغة اتفاقية فيينا إلى تخلف عدد من الفجوات الخارجية، منها ان واضئ واضعو

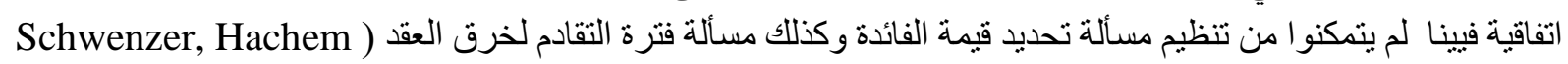
.(and Kee, 2012

يمكن الإشارة إلى قضية بولندية لجأت فيها المحكمة العليا إلى القانون المحلي لحل مسألة تحديد معدل الفائدة، إذ أبرم

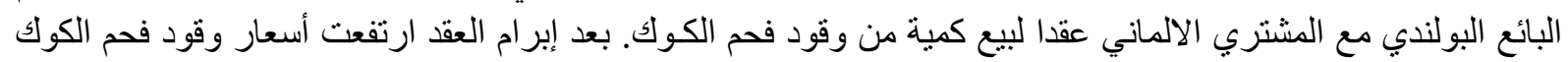

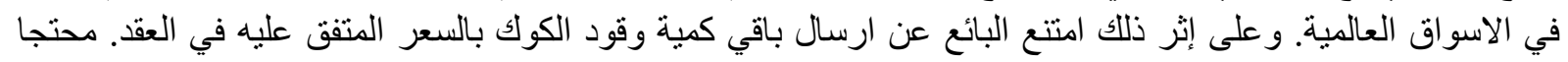

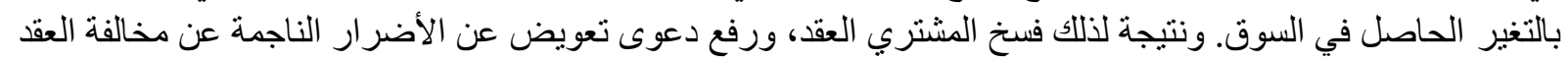
ومعظمها يتألف من رد قيمة وقود فحم الكوك غير المسلم اعتبار المن تاريخ اشعار الشعار الفسخ.

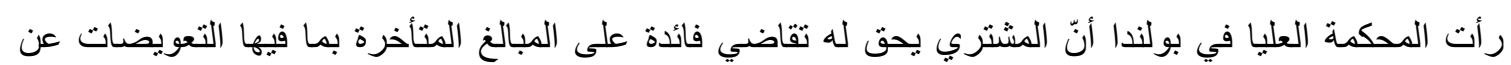

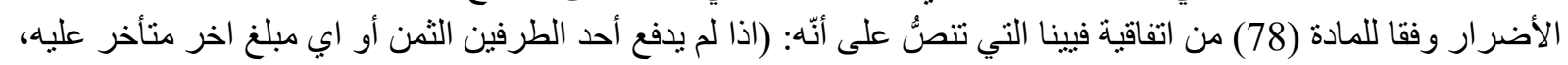

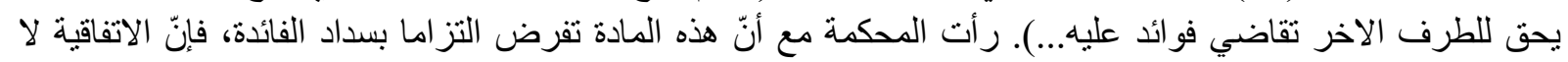

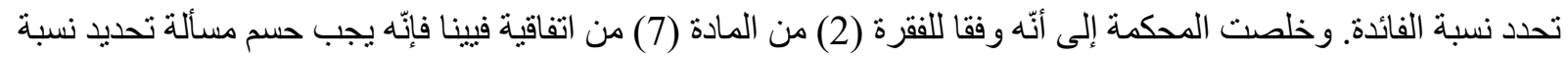

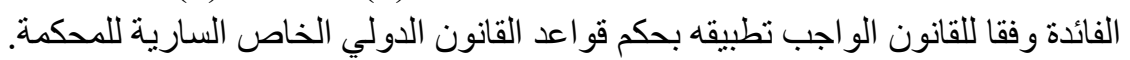

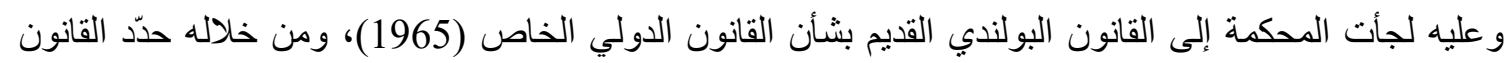

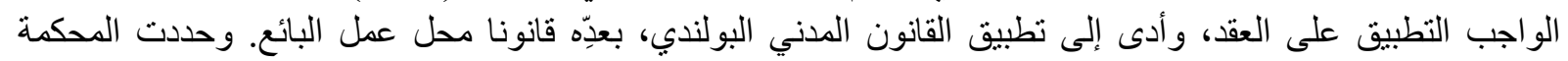

بموجبه معدل الفائدة (CLOUT Case 1306, 2008) 


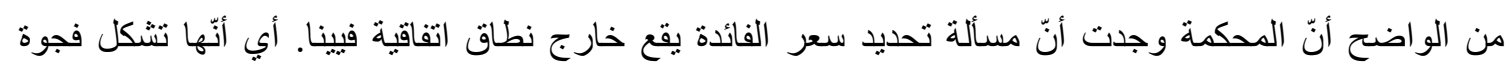

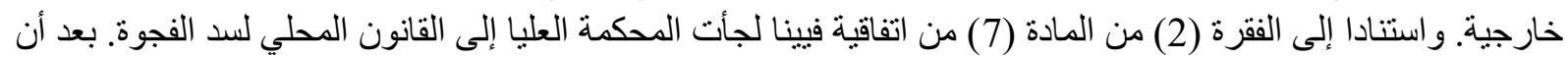

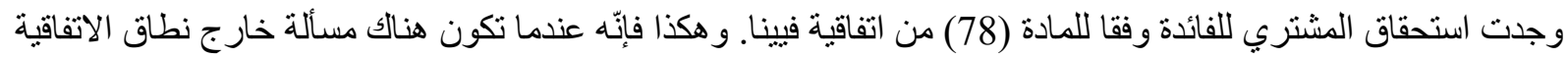
فإنّه يجب اللجو إلى إلى القانون المحلي.

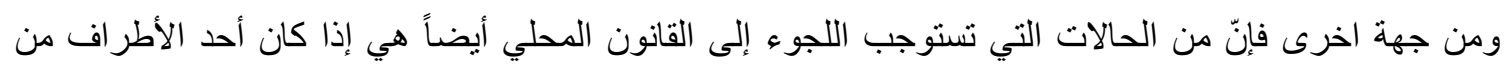

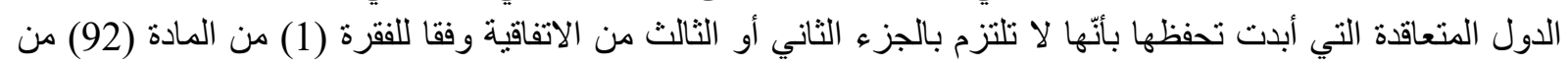

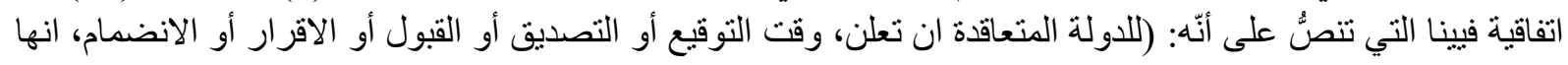

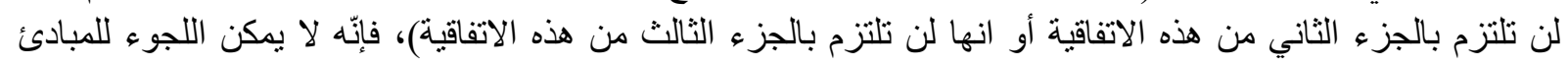

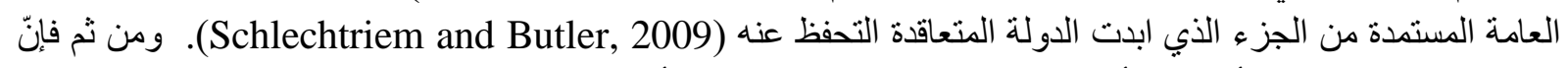

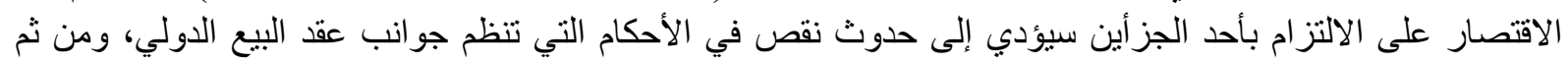

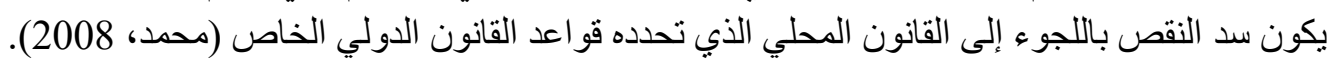

النتائج والتوصيات

النتائج:

إنّ مر اعاة الصفة الدولية لاتفاقية فيينا من شأنه أن يحقق التطبيق الموحد لنصوصها.

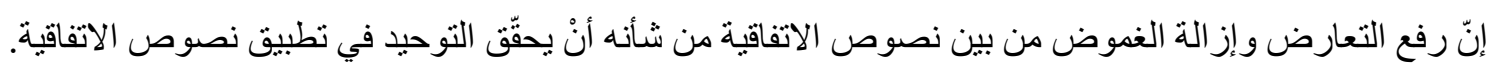

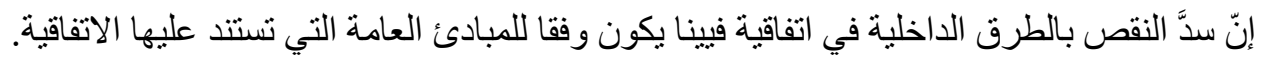

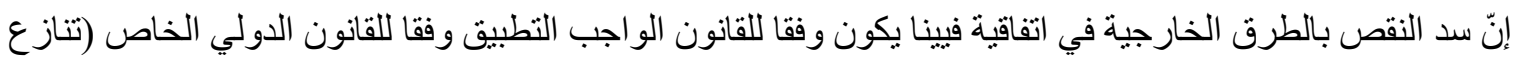

القو انين).

التوصيات:

ه العمل على القيام بمؤتمر ات دولية للقضاة والمحكّمين من أجل نوحيد الرؤى فيما يتعلّق بتطبيق نصوص اتفاقية فيينا.

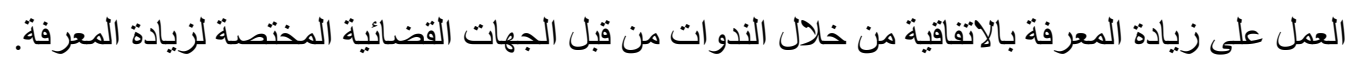

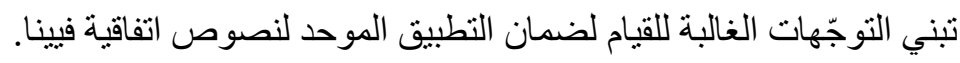
العمل على صياغة وثيقة تبيّن المبادئ العامة التي تستند عليها الاتفاقية بشكل نهائي. 


\section{المصادر والمراجع}

$$
\begin{aligned}
& \text { عطية، وليد. (2015). حل مشكلة التداخل (الطبعة الأوّلى). منشور ات الحلبي الحقوقية. }
\end{aligned}
$$

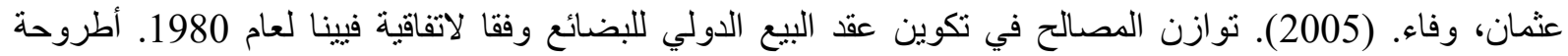

$$
\begin{aligned}
& \text { دكتور اه جامعة القاهرة، كلية الحقوق. } \\
& \text { الصغير، حسام. (2001). تفسير اتفاقية الامم المتحدة بشأن عقود البيع الدولي للبضائع. دار النهضة العربية. }
\end{aligned}
$$

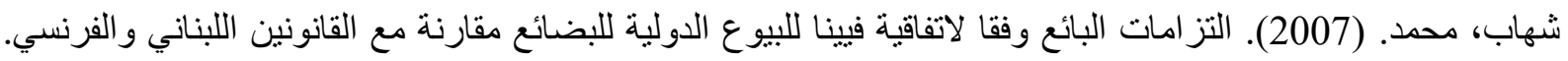

$$
\begin{aligned}
& \text { المنشور ات الحقوقية، بيروت. }
\end{aligned}
$$

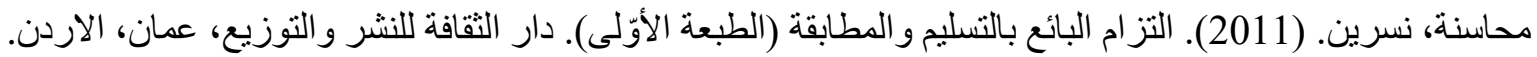

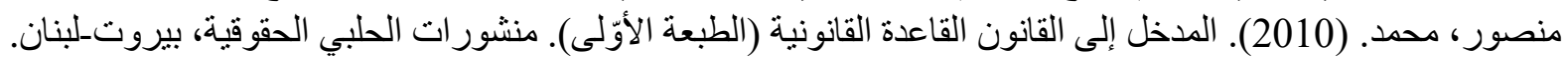

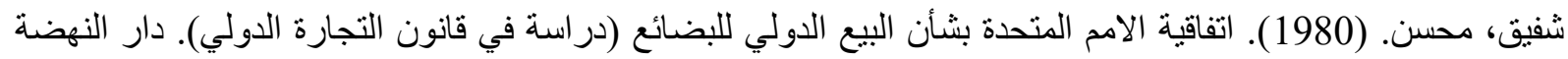

$$
\begin{aligned}
& \text { العربية. } \\
& \text { البكري، عبد الباقي \& بشير، زهير. (2019). المدخل لدر اسة القانون. العاتلك لصناعة الكتاب، بيروت. }
\end{aligned}
$$

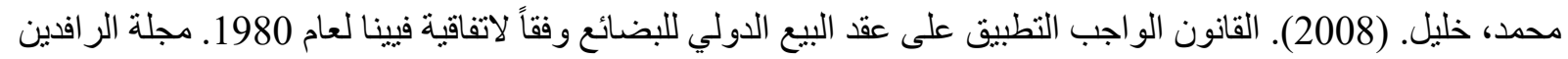

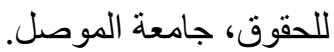

Author, A. A., \& Author, B. B. (Copyright Year). Title of the book (7th ed.). Publisher. DOI or URL

Schlechtriem, P. \& Butler, P. (2009). UN Law On International Sales The UN Convention On The International Sale Of Goods. Springer.

Komarov, A. (2005). Internationality, Uniformity And Observance Of Good Faith As Criteria In Interpretation Of Cisg: Some Remarks On Article 7(1). Jouranal Of Law And Commerce. 25(75), 75-85.

Felemegas, J. (2007). An International Approach to the interpretation of United Nations convention on contracts for the international sale of goods (1980) as uniform sales law. Cambridge University Press.

Sollund, M. (2007). The U.N. Convention On Contracts For The International Sale Of Goods, Article 7(1) The Interpretation Of The Convention And The Norwegian Approach. Nordic Journal Of Commercial Law. (1), 1-40. https://doi.org/10.5278/ojs.njcl.v0i1.3033

Medical Marketing International, Inc. v. Internazionale Medico Scientifica, S.r.l, 99-0380 U.S. District Court (1999). https://www.uncitral.org/clout/clout/data/usa/clout_case_418_leg1642.html (CLOUT Case No. 418)

Tribunale Di Pavia (1999). https://www.uncitral.org/clout/clout/data/ita/clout_case_380_leg1604.html?lng=ar

$1195 \quad 123 / 357 \quad$ Obergericht des Kantons Luzern (1997). https://www.uncitral.org/clout/clout/data/che/clout_case_192_leg-1081.html (CLOUT Case No)

Garro, A.M. (1989). Reconciliation Of Legal Traditions In The U.N. Convention On Contracts For The International Sale Of Goods. American Bar Association. 23(2), 443-483. https://www.jstor.org/stable/40706270

Maggi, M. (2004). Review Of The Convention On Contracts For The International Sale Of Goods (CISG). Kluwer Law International

Mistelis, L. (2005). The Unknown Factor, Article 55 CISG. Journal Of Law And Commerce. 25(285), 285-297.

10

$\mathrm{O}$

$72 / 00$

Landgericht

Darmstadt

(2000).

https://www.uncitral.org/clout/clout/data/deu/clout_case_343_leg-1567.html

(CLOUT

Case No. 343)

Jiang, Z. In Favor Of Appropriate Interpretation For The CISG, Legal Uniformity. 
Gillette, C.P. \& Scott, R.E. (2005). The Political Economy Of International Sales Law. International Review Of Law And Economic. https://scholarship.law.columbia.edu/faculty_scholarship/1362

Honnold, J.O. \& Flechtner, H.M. (2009). Uniform Law For International Sales Under The 1980 United Nations Convention 4th Revised Edition. Kluwer Law International.

Schlechtriem \& Schwenzer. (2016). Commentary on the UN Convention on the International Sale of Goods (4th ed.). Oxford University Press.

Schwenzer, I. \& Atamer, Y. \& Butler, P. (2014). Current Issues In The CISG And Arbitration, International Commerce And Arbitration. International Commerce And Arbitration. 15.

Buga, I. (2009). Taking The International Approach To The CISG: The Gap- Filling Role Of The UNIDROIT Principles And The Principles Of European Contract Law, Taking The International Approach To The CISG. Utrecht University.

Ferrari, F. \& Flechtner, H. \& Brand, R.A. (2004). The Draft UNCITRAL Digest and Beyond: Cases, analysis and unresolved issues in the U.N. Sales Convention. Sellier European Law.

3 Nd 509/02 Federal Supreme Court Of Austria (2002).

GÜL, I. (2016). Freedom Of Contract, Party Autonomy And Its Limit Under Cisg. Gül / Hacettepe HFD. 6(1), 77-102

Sica, L.C. (2006). apfilling In The CISG:May The UNIDROIT Principles Supplement The Gaps In The Convention?. Nordic Journal Of Commercial Law. (1), 1-28. https://doi.org/10.5278/ojs.njcl.v0i1.3044

N.V. A.R. v. N.V. I., 2001/AR/0180 Hof van Beroep, Gent (2002).https://www.uncitral.org/clout/clout/data/bel/clout_case_1017_leg-2462.html (CLOUT Case 1017)

Janssen, A. \& Meyer, O. (2009). CISG Methodology. Sellier (2016). UNCITRAL Digest of Case Law on the United Nations Convention on Contracts for the International Sale of Goods. United Nations Commission On International Trade Law.

Rheinland Versicherungen v. S.r.l. Atlarex and Allianz Subalpina s.p.a., Tribunale di Vigevano (2000). https://www.uncitral.org/clout/clout/data/ita/clout_case_378_leg-1602.html (CLOUT Case 378)

Ferrari, F. (1994). Uniform Interpretation Of The 1980 Uniform Sales Law. Georgia Journal Of International And Comparative Law. 24(2), 184-226. https://digitalcommons.law.uga.edu/gjicl/vol24/iss $2 / 2$

Schwenzer, I. \& Hachem, P. \& Kee, C. (2012) Global Sales And Contract Law. Oxford University Press.

T.K.M.E. GmbH (German buyer) v. P.K. S.A. (Polish seller), V CSK 63/08 Supreme Court (2008). https://www.uncitral.org/clout/clout/data/pol/clout_case_1306_leg-3072.html (CLOUT Case 1306) 